\title{
Education in Pakistan's Punjab: Outcomes and Interventions
}

\section{Masooma Habib*}

\begin{abstract}
One of the most critical challenges Pakistan faces today is the need to improve and expand its education system. With important political and demographic changes taking place, greater devolution and strengthened democracy, this is an opportune moment to build a better system. Not only does the purpose of education have to be defined beyond what has been left over from colonial administrative objectives, but a much greater effort has to be invested in developing the skills and talents of the majority of the population.

Punjab, Pakistan's largest province, has taken several education reform initiatives to improve education outcomes. However about a quarter of school age children are still not attending school either because they never enrolled or because they dropped out early. Low transition rates to secondary education are of special concern. Moreover, recent assessments have shown that students' knowledge and comprehension of basic subjects remains alarmingly low. Improved learning in schools is therefore another important challenge. Patterns in learning achievement in Punjab indicate the importance of school level factors, implying that a good school could make up for other regional and socio-economic disparities. Better quality schools also attract more students from the poorest families, because when parents expect better returns from education, the time and resources spent on schooling becomes worthwhile. This paper will review the extent to which critical gaps in achievement levels and other educational outcomes have been addressed by past policies and current reform programs.
\end{abstract}

Keywords: Education, schooling, Pakistan.

JEL classification: I21.

\section{Introduction}

Almost half of Pakistan's population is illiterate and a quarter of school-age children do not attend school. The problem of nonattendance is most acute in rural areas and for girls. The low priority given to education

\footnotetext{
* Senior Fellow, Center for Research in Economics and Business (CREB), Lahore School of Economics, Pakistan. The author would like to thank her colleagues Anum Bukhari and Asha Gul for their assistance and Shehryar Nabi for help with editing.
} 
is reflected in the fact that Pakistan spends only 2 percent of its GDP on this sector-among the lowest levels in developing countries. Even these limited resources are not spent efficiently since learning achievements for the majority of students are below standard. Since 40 percent of the population is below 15 years old, enhancing their skills and wellbeing is one of the country's most important challenges. With the consolidation of democracy following the May 2013 elections, an expanded, high-quality education system becomes even more urgent to enable the country to move forward in its social and economic development.

This study provides an overview of schooling in Punjab, Pakistan's largest province and home to almost 60 percent of its population. Section 2 discusses the vision that establishes the context for a country's education system. Section 3 outlines Punjab's education achievements. Section 4 presents a framework for assessing the major interventions undertaken to improve education outcomes, and notes where progress has been made and which issues need attention. Section 5 concludes the study.

\section{An Education Vision and its Implementation}

In the mid-19th century, many countries that are now considered developed, launched public education to instill a sense of national cohesion among their citizens and develop the basic skills required by newly industrializing economies. Variations in education systems emerged from countries' unique institutional and cultural backgrounds (Cummings, 2003). For instance, Japan emphasized schools primarily for the purpose of preparing industrial workers rather than developing individual talent. Britain's education system started out with the objective of promoting an elite class, and Germany's more centralized system promoted early streaming in primary and middle school to develop specialized skills. Most developing countries with colonial backgrounds inherited the systems their rulers had introduced.

In 1947, Pakistan and India inherited a colonial system designed to prepare government and army officers to work for their British rulers. While the purpose of this education system for the Subcontinent was clear, Pakistan has yet to define a clear postcolonial objective of education. A policy objective of investing in education for the purpose of developing the basic skills of all citizens for economic and social development still has to be clearly articulated and implemented by the federal and provincial governments. 
It may be that this lack of a clear vision has resulted in the government's failure to commit steadily to investing in education and improving outcomes. Pakistan's enrollment rates lag behind those of its South Asian neighbors (Figure 1). Such low enrollment rates have serious consequences for the county's development objectives.

Figure 1: Gross enrollment: Regional comparisons

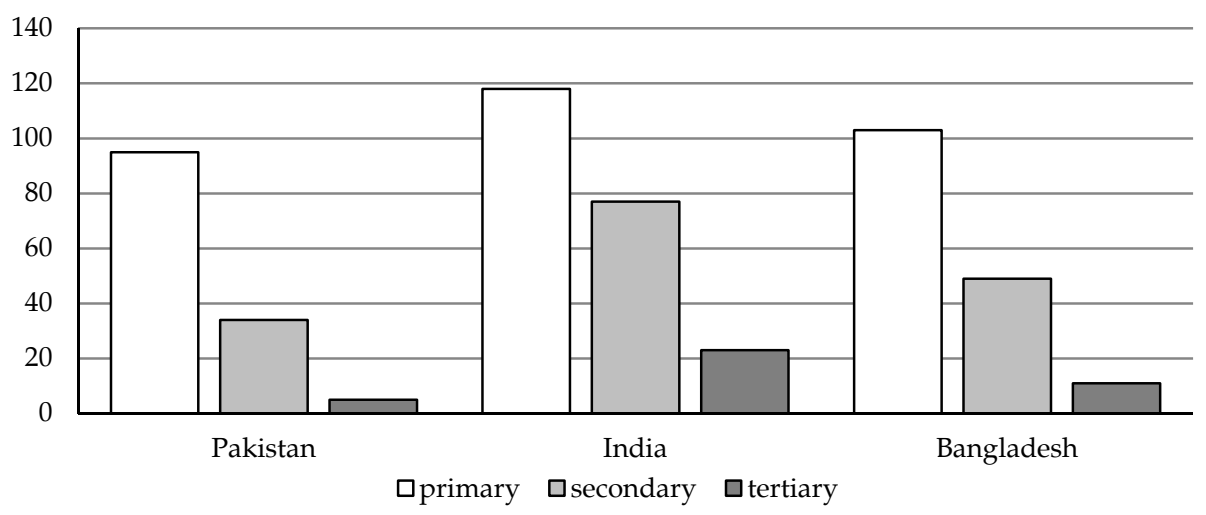

Source: World Bank (2012).

An opportunity to construct a vision for education exists in the ongoing decentralization process in Pakistan. Building on the initial decentralization of provincial administrative structures in 2001, the $18^{\text {th }}$ Amendment to the Constitution in 2010 has fully devolved education and health to the provinces. With the omissions of the concurrent list in the constitution, provincial governments are now responsible for education planning, policy, curricula, and standards. Each province has to develop its own budget and action plan for education, and the provincial education and law departments are responsible for drafting legislation to implement the new devolved structure. ${ }^{1}$

Education is also compulsory by law for the first time. Article 25-A of the 18 $18^{\text {th }}$ Amendment states: "The State shall provide free and compulsory education to all children of the age of five to sixteen years in a manner as may be determined by law." The Punjab education department has drafted a "Right to Education" bill (2013), which is currently being presented to the Punjab government for approval; provincial legislation on the implementation of

\footnotetext{
${ }^{1}$ Concerns about ensuring minimum curriculum standards in the absence of uniform regulations have led to suggestions about a possible federal role in monitoring education. An option recommended by the Report of the Parliamentary Committee on Constitutional Reforms was to place curricula under the mandate of the Council of Common Interests or Federal Legislative List Part II.
} 
Article 25-A is still pending. ${ }^{2}$ To implement Article 25-A, provincial governments will need to increase their education budgets and manage the National Finance Commission award efficiently. ${ }^{3}$

Research in education reforms repeatedly emphasizes that merely spending more money on education and on building school systems does not necessarily lead to better learning and improved worker productivity (Pritchett, 2001). The development impact of investments in education depends on governance structures, the extent of demand for newly developed skills, and the quality of education imparted.

On the other hand, in a comparative study of India and China, Dreze and Sen (2013) argue that state investment in education and health is the key to increased productivity, growth, and development. According to the authors, the majority of the population-especially the poorest groups in society-gains more from expenditures on health and education as opposed to spending on inefficient, poorly targeted subsidies on items such as diesel fuel.

A unique feature of Pakistan's education system is the rise of lowcost private schooling, particularly in Punjab (comprising up to a quarter of total enrollments), reflecting the significant demand for education. Parents may prefer private schools for several reasons: they may be located closer to home, especially for girls at the primary level; teachers attend class more frequently; and the quality of teaching at the middle and secondary levels - when examination preparation becomes important-is likely to be better (Ahmed, Amjad, Habib, \& Shah, 2013). The quality of education is, overall, relatively better in private schools; they also function more efficiently since teachers' salaries reflect their performance and the cost of education is considerably lower than in public schools (Andrabi, Khan, Khan, \& Naseer, 2012). Moreover, private school graduates in Pakistan are estimated to earn more than their counterparts in Bangladesh, indicating that the regulatory framework may be more conducive to operating private schools in Pakistan (Asadullah, 2009). These insights from the experience of private schools can help formulate policies aimed at delivering effective schooling in the government sector.

${ }^{2}$ Of the other provinces, so far only Sindh and the Islamabad Capital Territory have passed the compulsory education bill; Khyber Pakhtunkhwa (KP) and Balochistan have yet to draft the legislation.

${ }^{3}$ Federal tax revenues still provide the major portion of education financing, which is distributed to the provinces on the basis of the National Finance Commission awards. The provincial finance commissions then transfer funds to the district governments. 
One conclusion we can draw from the evidence presented in the empirical research is that an expanded and elaborate education reform program is not necessarily a sufficient condition for higher productivity and higher economic growth, but without educated workers, higher productivity cannot continue. The challenge of education reforms is to efficiently implement an investment program to support a high-quality education system suited to local demand and employment opportunities.

\section{The State of Education in Punjab}

Compared to the other provinces, Punjab has the highest participation rates among school-age children (Figure 2). ${ }_{4}$ There are currently about 60,000 government schools and 35,000 private schools in Punjab, spread across 36 districts. Government schools are administered at the district level, and districts are further subdivided into tehsils and clusters. One education district officer per district provides the main administrative link to the provincial government and plays a key leadership role in the delivery of education. Education district officers are assisted by two or more assistant education officers.

Punjab's elaborate education administrative structure, however, has produced poor outcomes. Low enrollment rates (reflecting children who have never attended school as well as early dropouts), low levels of learning in schools, inadequate access to schooling for girls, and poor transition to middle and higher levels of education are of particular concern. Moreover, the poorest households and southern districts show the least numbers of children enrolled.

\footnotetext{
${ }^{4}$ Figure 2 is based on school enrollment data by age to assess the overall proportion of children in school according to the compulsory schooling requirements set by Article 25-A.
} 
Figure 2: Percentage of 5-16-year-olds in school

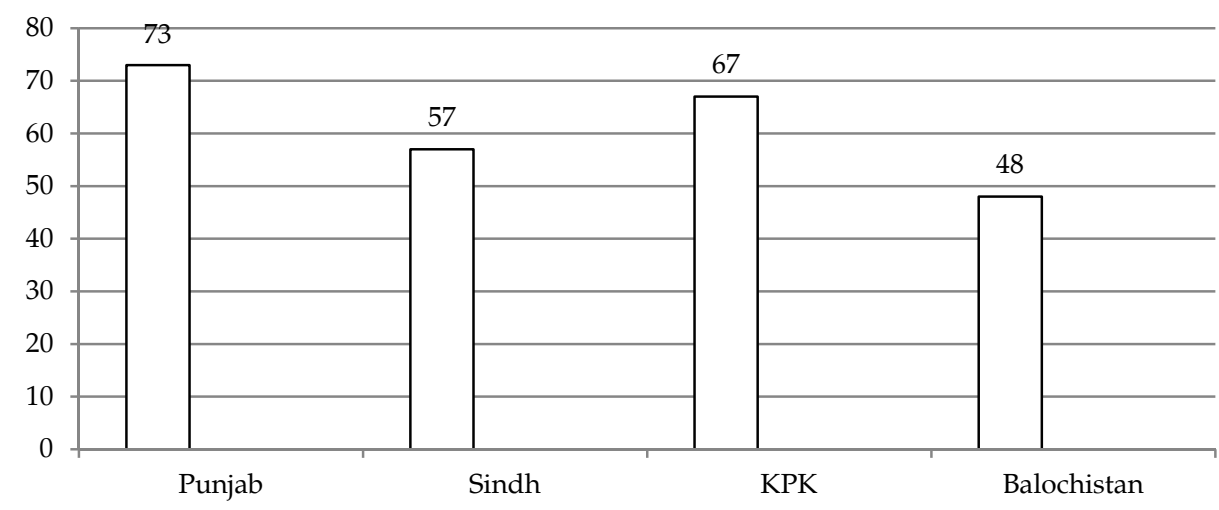

Source: Pakistan Bureau of Statistics (2011).

The absence of census data makes estimating net enrollment rates (NERs) ${ }^{5}$ especially problematic because data on the total number of schoolage children in the country and in the provinces are based on projections that vary by source. ${ }^{6}$ Moreover, the incidence of overage and underage children as well as repeaters reduces the accuracy of calculating NERs. The large number of children in katchi or pre-primary classes should also be taken into account since many five- and six-year-olds attend pre-primary classes, and delayed entry into primary school is fairly common in rural areas.

Table 1 below gives NER estimates, including pre-primary enrollments, since substantial overlap in primary and katchi age groups is expected. Data for middle and high schools shows specific age groups corresponding to grades $6-8$ and grades 9 and 10, respectively. The data indicate that children in middle and high schools tend to be in older age groups within the categories used to calculate NERs.

\footnotetext{
${ }^{5}$ NERs measure the number of age-appropriate children in school as a proportion of school-age children for a particular level.

${ }^{6}$ Calculating net and gross enrollments is problematic because accurate numbers for the school-age population are not available. Following the last population census in 1998, data collection for a new census started in 2011 but has not yet been completed. Without an updated census, the evidence for assessing outcomes consists of estimates based on surveys and projections of the population.
} 
Table 1: NERs in Punjab, 2010/11 (\%)

\begin{tabular}{|c|c|c|c|c|c|c|c|c|c|c|c|c|c|c|c|}
\hline & \multicolumn{3}{|c|}{$\begin{array}{c}\text { Primary and } \\
\text { katchi } \\
\text { (4-9 years) }\end{array}$} & \multicolumn{3}{|c|}{$\begin{array}{l}\text { Middle school } \\
\text { (10-12 years) }\end{array}$} & \multicolumn{3}{|c|}{$\begin{array}{l}\text { Middle school } \\
\text { (11-13 years) }\end{array}$} & \multicolumn{3}{|c|}{$\begin{array}{l}\text { High school } \\
\text { (13-14 years) }\end{array}$} & \multicolumn{3}{|c|}{$\begin{array}{l}\text { High school } \\
\text { (14-15 years) }\end{array}$} \\
\hline & $\mathbf{M}$ & $\mathbf{F}$ & $T$ & $\mathbf{M}$ & $F$ & $T$ & $\mathbf{M}$ & F & 1 & $\mathbf{M}$ & $\mathbf{F}$ & $T$ & $\mathbf{M}$ & 1 & $T$ \\
\hline 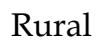 & 67 & 61 & 64 & 2 & 17 & 19 & 34 & 29 & 31 & 11 & 11 & & 1 & S & 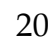 \\
\hline rban & 80 & 77 & 79 & 2 & 34 & 31 & 0 & 51 & 40 & 17 & 25 & & 32 & 38 & 35 \\
\hline otal & 70 & 66 & 68 & 23 & 22 & 23 & 37 & 36 & 37 & 13 & 16 & 14 & 24 & 25 & 25 \\
\hline
\end{tabular}

Note: $\mathrm{F}=$ female, $\mathrm{M}=$ male, $\mathrm{T}=$ total.

Source: Pakistan Bureau of Statistics (2011).

A higher proportion of middle school children fall in the older age groups, so children older than nine are expected to be in primary school but are not included in net enrollment calculations. Children older than 15 are also enrolled at matriculation level or in high school, although this is not reflected in the NER data. Government schools do not deny admission to children who want to attend, so having children of various ages and skill backgrounds makes it difficult to teach at grade-appropriate levels.

Although net enrollments do not capture accurate levels of school participation, the data indicate substantial differences between urban and rural and male and female enrollments. There are sharp drops in overall enrollment at the high school level, but girls who make it beyond middle school tend to drop out less than boys at the high school level, especially in urban areas.

To help picture trends in school participation since the introduction of major education reforms in 2003 in Punjab, Figures 3, 4, and 5 illustrate data on gross enrollments ${ }^{7}$ from 2004 to 2011. Primary enrollments rose from 2004/05 to 2007/08, after which they declined with only modest improvements up to 2011 (Figure 3). Boys' middle school enrollments remained fairly stagnant over the period. Girls' middle school enrollments increased substantially from 2006 to 2008, but declined the following year (Figure 4). Secondary school enrollments show greater increases in girls' participation rates although overall enrollment levels are higher for boys. The gap between male and female enrollments persists, although it narrows due to the rise in girls' middle school enrollments around the time the scholarship stipend for middle school girls was introduced.

${ }^{7}$ Gross enrollment rates measure total enrollments irrespective of age as a proportion of total children in the expected age group at that education level. 
Figure 3: Primary school gross enrollments, 2010/11

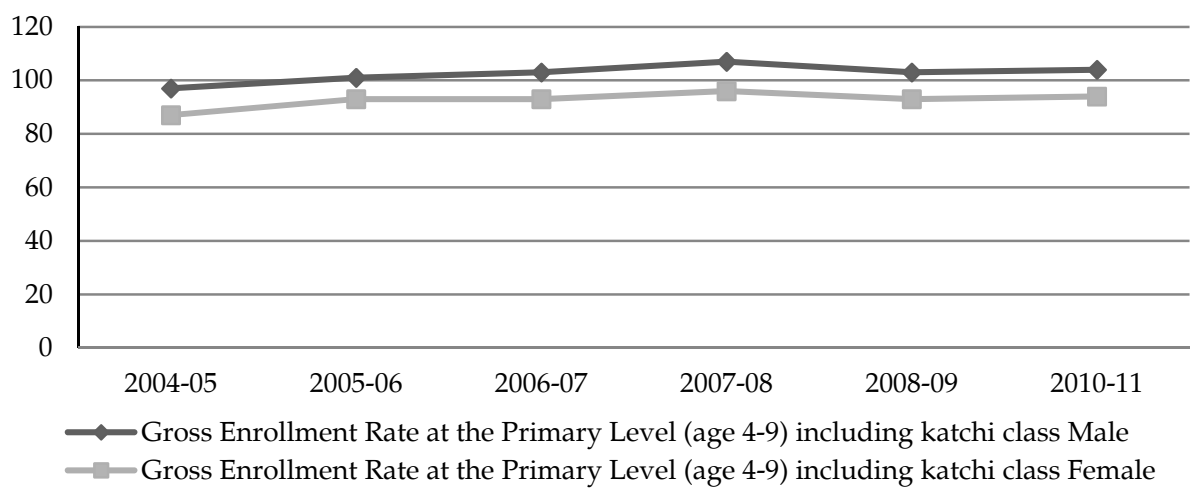

Source: Pakistan Bureau of Statistics (2011).

Figure 4: Middle school gross enrollments, 2010/11

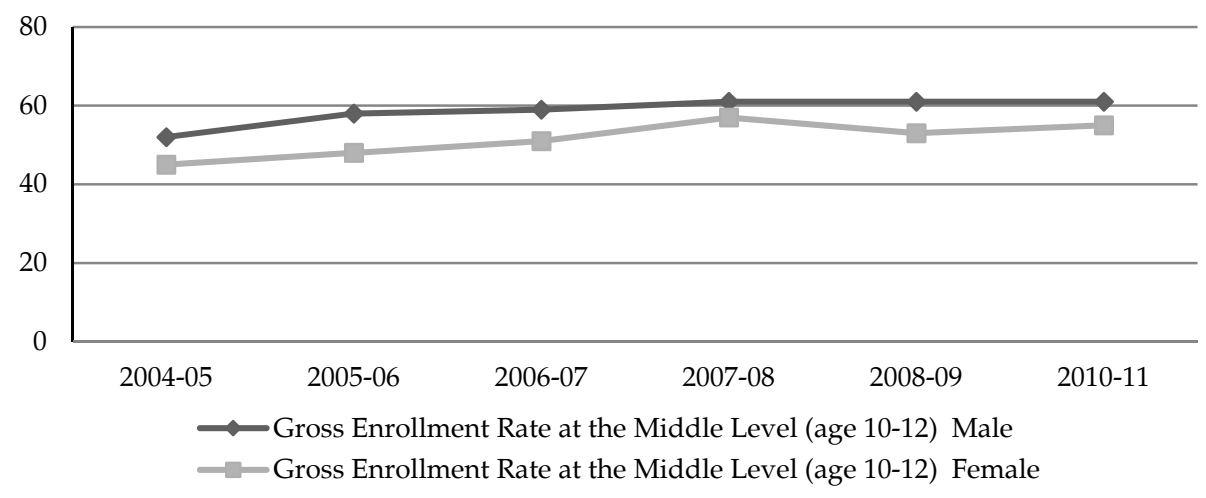

Source: Pakistan Bureau of Statistics (2011).

Figure 5: Secondary school gross enrollments, 2010/11

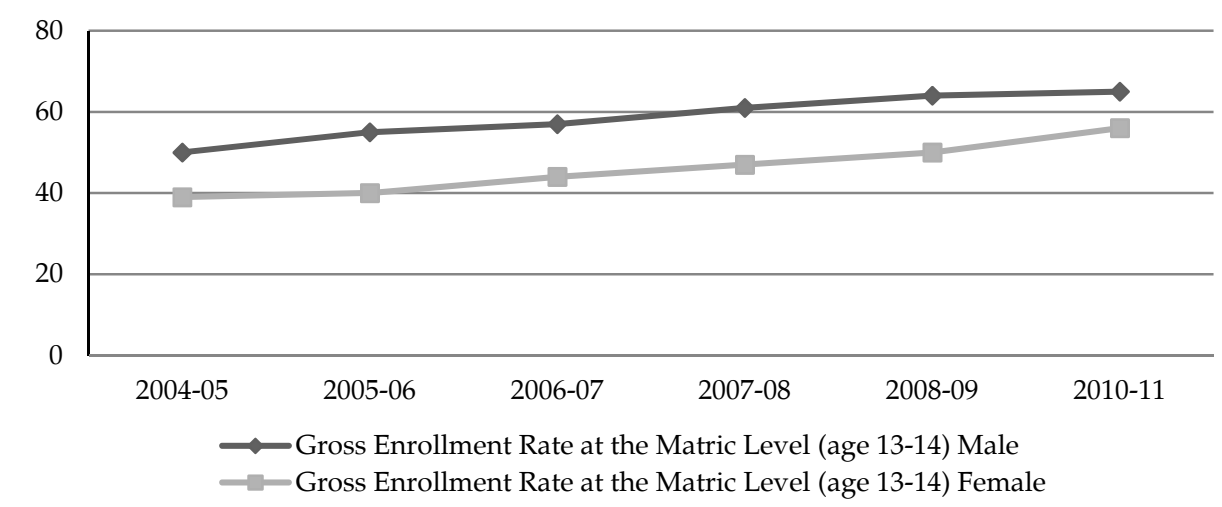

Source: Pakistan Bureau of Statistics (2011). 
A number of critical gaps remain in Punjab's education system:

1. Too many children are still out of school. An estimated 7 million children belonging to the relevant age group are out of school, and half of these children are in Punjab (Pakistan, Ministry of Education and Training, 2013). Girls and children from the southern districts make up a higher proportion of out-of-school children. Figure 6 shows that, in three southern districts, over 30 percent of 6-16-year-olds do not attend school, and in seven districts, four of which are in the south, 20-30 percent of children are out of school.

Figure 6: Out-of-school children by district

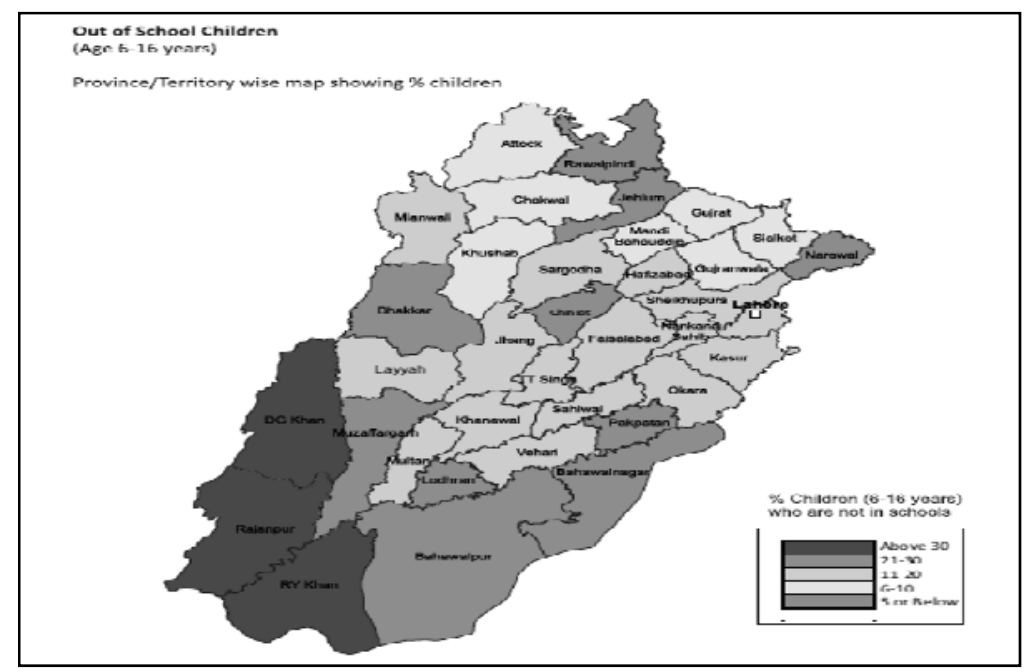

Source: Annual Status of Education Report (2013).

2. The poorest households have the least access to education. The proportion of out-of-school children is highest in the lowest income quintile. Half of 5-18-year-olds (and 63 percent of females) in the lowest income quintile had never attended school, compared to 38 percent of the same age group (and 47 percent of females) in the highest income quintile (Pakistan Bureau of Statistics, 2010). The Annual Status of Education Report (ASER) (2013) also reports that the poorest quintile has the most (46 percent) out-of-school children.

3. Girls' participation lags persistently behind that of boys. Girls from poor households in rural areas are least likely to be in school and "suffer a triple disadvantage, with their poverty and rural location compounding the gender-based disadvantage experienced by their better-off urban peers" (Lloyd, Mete \& Grant, 2007). In Figures 3, 4, 
and 5 above, data from the Pakistan Living Standards Measurement Surveys for 2004-11 on male and female enrollments show that the gender gap in enrollment has persisted over time. However, increases in girls' middle school enrollments in 2007, continuing onto increased secondary enrollments, indicate the effect of policies targeted to improve girls' enrollment.

4. Enrollments drop after the primary grades. There is limited opportunity to obtain education beyond the primary level. As Figure 1 shows, fewer students progress onto secondary education in Pakistan compared to India and Bangladesh. In a comparison with other developing countries, the proportion of places per grade at the secondary level compared to the primary level are much lower in Pakistan; in Iran and Sri Lanka, for instance, the proportion is 100 percent compared to 46 percent in Pakistan (Lynd, 2007).

5. Inadequate learning levels. The gauge of a good education system is the availability of high-quality education for every child. Results based on examinations in grade 4 introduced by the Punjab Examination Commission (PEC) show that most students in public and private schools have basic proficiency in mathematics, language, and social studies (Figure 7). ASER also carries out assessments of learning, and its 2012 report shows that only 40 percent of 6-16-year-olds could read a second grade-level sentence in Urdu or their mother tongue and perform basic arithmetic (ASER, 2013). Although there was a slight improvement in overall reading and mathematics on average compared to the figures in the previous year's report (ASER, 2012), absolute learning levels in both government and private schools continue to be low.

Figure 7: Skills in math, language, and social studies (grade 4 assessments)

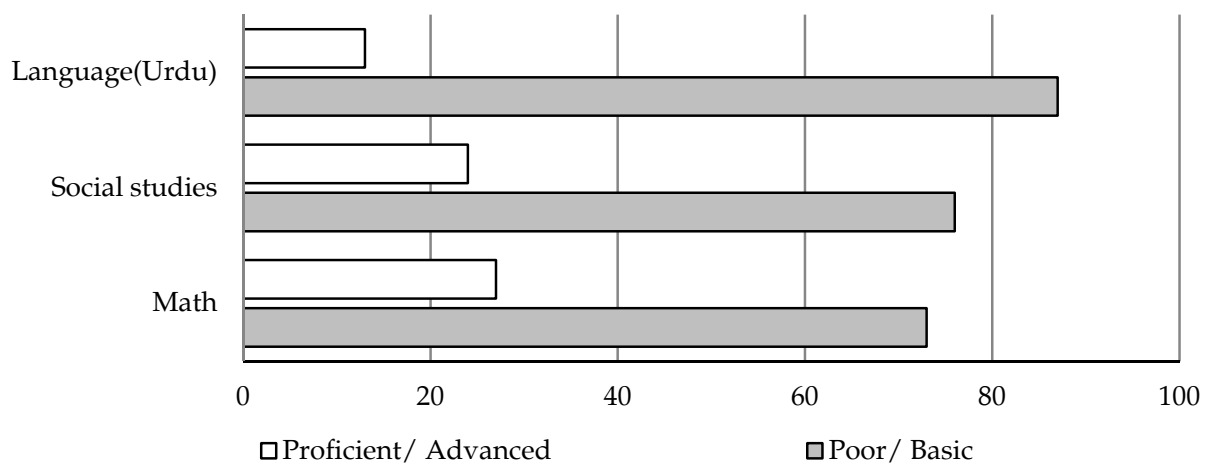

Source: Punjab, School Education Department (2011a). 


\section{Interventions and Outcomes}

The limited success in education is not for want of reforms. Several education programs and policies have been introduced since independence in 1947. In a review of the history of national and provincial education policy and reform in Pakistan, Bengali (1999) gives a comprehensive list of the many intended programs designed as a matter of bureaucratic routine, whose targets and goals were seldom met.

While the bulk of education funding continues to be on salaries and infrastructure, recent initiatives in Punjab's education policy are aimed more consciously at increasing student enrollment and learning. Current donor and government programs in education revolve around access, quality, and governance, and several innovative schemes have been introduced for better delivery of these outcomes. Section 4.1 presents a framework for assessing recent interventions (policies, programs, and projects) aimed at improving Punjab's education outcomes.

\subsection{A Framework for Assessing Interventions}

Various school and household characteristics play a role in aiding or constraining educational goals. Influences at home as well as school can have an effect on whether students enroll in the first place, how well they learn, and if they stay in school. A child's innate talents and his/her home and school environments-in which learning takes place-are also important determinants of educational achievement.

Figure 8 presents a broad framework for looking at supply- and demand-side influences on educational outcomes identified by the education literature. Demand-side influences include household income, parents' education, distance from home, number of siblings, and job opportunities. Supply-side influences include investment in textbooks, school buildings and facilities, teacher training, availability of jobs, and higher education opportunities. Children's school attendance depends, therefore, on whether (i) their households can afford to send them to school, (ii) schools are available close by and it is safe to travel there, and (iii) parents value the education offered by these schools. A child is more likely to remain in school if (i) high-quality middle and secondary schools are accessible, (ii) his/her parents can continue to afford their child's education, (iii) the school environment is satisfactory, and (iv) teachers are present. All these factors are influenced by the common platform of the regulatory, governance, and financial structures in which education delivery takes place. 
Demand and supply factors are also interrelated. For example, the quality and type of schooling and teacher availability will influence parents' demand for education-poor parents might not consider it worthwhile to devote their children's time and household resources to poor-quality schooling that is not perceived to impart better skills or employment opportunities than could be gained without the education. Student attendance and motivation to study also depends on the quality of instruction, the school environment, and principal leadership.

Figure 8: Factors influencing educational access and learning

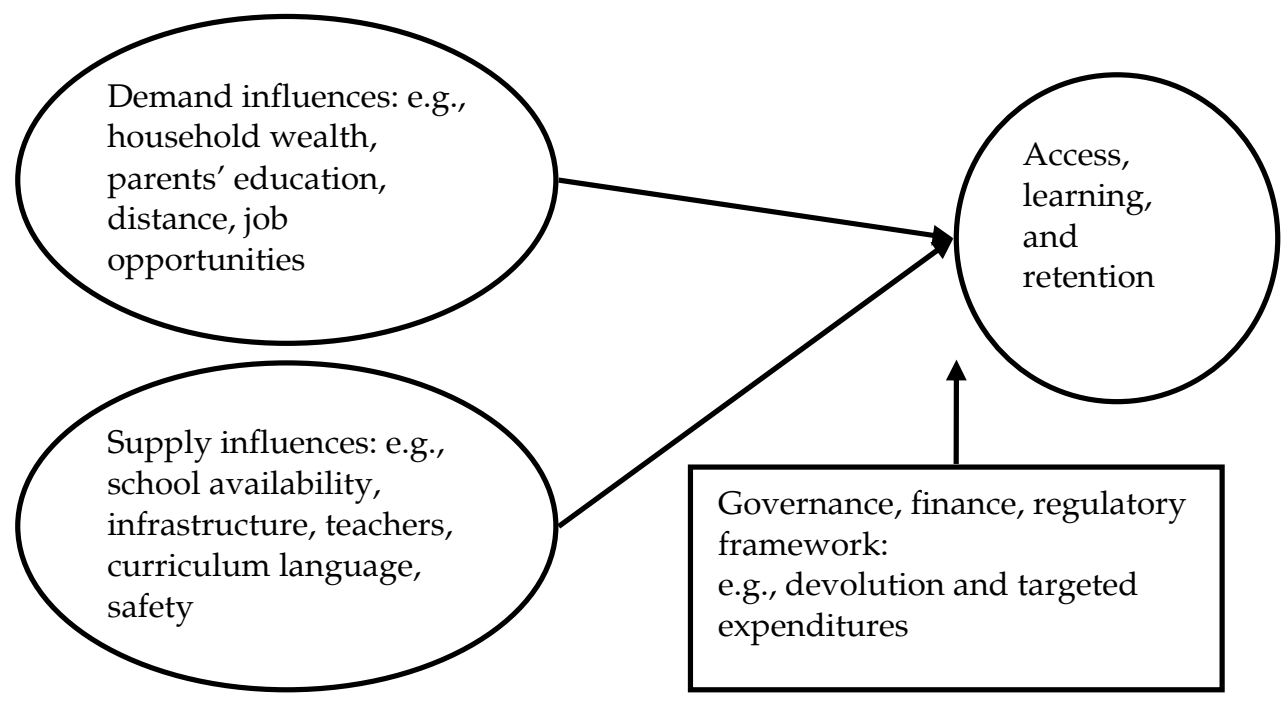

Many studies have identified various demand and supply factors explaining educational achievement. In the earlier literature, parents' socioeconomic status was given as one of the major reasons for investing in education. Subsequent studies have emphasized the role of school inputs such as teacher training and school infrastructure (Orazem \& King 2007; Glewwe \& Kremer, 2006). For Punjab's primary schools, important demand-side factors influencing school participation and performance include poverty and the distance to school. However, student performance varies the most across schools and not across poorer or richer districts. This implies that improving school-level factors could help overcome some of the demand-side constraints associated with families' lower socioeconomic levels (Das, Pandey, \& Zajonc, 2006; Andrabi, Das, Khwaja, Vishwanath, \& Zajonc, 2007; Andrabi et al., 2012).

Supply-side initiatives that make school a pleasant experience with actual learning leading to better opportunities and wellbeing seems to be 
the key to better education outcomes. However, it is difficult to pinpoint the specific school and teacher characteristics that improve educational outcomes. A review of a large number of studies across several countries conducted over 1999-2010 reveals that only a few school and teacher characteristics have a significant impact on learning and dropouts. These can include teachers' subject knowledge, low teacher absenteeism, and the availability of desks (Glewwe, Hanushek, Humpage, \& Ravina, 2011).

\subsection{Punjab Education Reform Initiatives}

The Punjab Education Sector Reform Program (PESRP), which started in 2003, has undertaken major investments in education. Funded by the World Bank and the UK Department for International Development (DFID), the PESRP uses disbursement-linked indicators to disburse funds on the fulfillment of at least eight out of ten such agreed indicators. The Punjab government meets most of the PESRP's cost (about USD 3.5 billion) with support from donors, mainly the World Bank (USD 350 million) and DFID (USD 200 million). The PESRP was introduced with three overarching goals: improving access, quality, and governance in education. A devolved administrative structure with increased targeting of educational expenditures to poorer households was also planned. However, the program's general impact has not been significant: the enrollment trends given in the previous section show stagnating primary and middle school enrollments over the reform period, with only secondary school girls' enrollments increasing in some years.

The Punjab Schools Reform Roadmap was initiated in 2010 under a broader DFID-funded program, formulated especially as a framework to expedite the delivery of educational results under the PESRP. The program's administrative structure involves keeping track of progress on the education outcomes of schools and districts, and the results are reported directly to the chief minister of Punjab every two or three months. Under the roadmap program, a significant rise in the number of school visits by monitoring teams has helped improve student and teacher attendance in the two years that it has been implemented (Barber, 2013).

The urgent approach taken under the roadmap depends on the commitment of the highest-level officials. Should this commitment wane, there may be a slump in education outcomes if the system relies too heavily on the roadmap framework. Moreover, ranking performance by districts may be misleading if there is wide variation among schools within districts (Andrabi et al., 2012). A closer look at these variations across 
schools is important in explaining why some schools perform better than others and in using these existing examples of what works as standards for improvement rather than relying on average district-level performance.

However, the roadmap has created a dataset of schools and a monitoring system to jumpstart the Punjab school system into performing better. It provides a useful overall framework in which the details of teacher, subject, and curriculum quality can be worked out as long as excessive political pressure is not imposed on districts to force results out of schools and students-a process that normally takes time.

As mentioned earlier, salaries and physical infrastructure absorb the bulk of government budgets, usually leaving little room for experimenting with innovative programs. Donor-assisted programs allow flexibility to try new interventions to improve education; based on their results, these reforms can be scaled up and new policies introduced. Major reform initiatives can be assessed in the overall framework of factors influencing education outcomes.

\subsection{Demand-Side Initiatives}

On the demand side, policies being followed include the girls' stipend program, school vouchers, and conditional cash transfers (CCTs) under the Benazir Income Support Program (BISP)—a large-scale social protection program targeting women in low-income households and currently reaching up to 4 million households in Pakistan.

\subsubsection{Female Secondary School Stipend Program}

This program was introduced as one component of the PESRP in 2004, designed to improve female enrollments by addressing the demandside constraints of affordability and distance. The stipend was implemented in 15 districts with low female literacy levels and girls in grades 6-8 were awarded a cash transfer of PRs 600 every three months if they met the 80 percent school attendance criterion. Since distance to school has been identified as an important constraint, the program was also meant to encourage parents to spend on transporting girls to school. In 2006, the stipend program was extended to high school girls and the amount of the stipend has also been increased. Chaudhury and Parajuli (2010) indicate that enrollments for secondary school girls may have increased by 9-20 percent, depending on the data sources. However, the authors do not find any significant improvement in learning among girls in the stipend districts. 


\subsubsection{Education Voucher Scheme}

This scheme addresses the poverty constraints faced by parents and is designed to attract out-of-school children. Started in 2006, the voucher program was set up by the Punjab Education Foundation, 8 developed in response to the success of low-cost private schooling in Pakistan, especially in Punjab. Under this scheme, students who would otherwise not be able to afford an education can use vouchers of up to PRs 350 to attend private schools. Expanding the voucher scheme is expected to increase enrollments. However, unlike schools in the private sector, the voucher scheme entails administrative effort and expense to monitor learning assessments and identify deserving students and strategic school locations to receive vouchers.

A study on parents' perceptions of school choice finds that a unit increase in expenditure on private schooling relative to public schooling decreases the probability of female enrollments in private school by 13 percent. For males, this factor is insignificant in explaining school choice. This implies that the cost of schooling is a key factor in deciding on the type of school for girls, but not for boys (Ahmed at al., 2013). An extension of the voucher scheme could be used to target a higher proportion of girls since the research indicates that parents are willing to spend more on boys' education.

\subsubsection{Waseela-e-Taleem}

The Waseela-e-Taleem program was launched under the BISP in 2012. The program aims to help enroll out-of-school children and encourage families to continue schooling those who are already enrolled. A beneficiary family is eligible for a cash transfer of PRs 200 a month for up to three children on meeting the admission requirements of a verified school and fulfilling a 70 percent minimum quarterly school attendance criterion. In January 2013, about 50,000 families were enrolled in the program and it is estimated that by 2015 more than 2 million children will be enrolled (Nabi, 2013). Using a phased implementation approach, the program will be tested in selected districts and scaled up based on the results of the pilot. A rigorous evaluation of the program has been built into the BISP's implementation structure but the results of the first phase of testing are not yet available.

\footnotetext{
8 The Punjab Education Foundation was established as an autonomous body through a parliamentary act in 1991 to set up public-private partnerships between government and private institutions to extend quality education to low-income families.
} 
While CCTs have been effective in raising enrollments and improving student progression to higher grades, their impact on students' academic achievement is harder to measure. Research on a large-scale primary scholarship pilot program in Cambodia compares the results of targeting scholarships based on merit with scholarships based on poverty ranking (Barrera-Osorio \& Filmer, 2012). Enrollment and school progression was favorable in both approaches, but the achievement impact is greater only in the merit-based approach, implying that students and households would be more motivated to obtain an education under a merit-based voucher scheme.

\subsection{Supply-Side initiatives}

Past and current education policies on the supply side include school infrastructure facilities, contract teachers, the provision of free textbooks, teacher professional development, student assessments, and effective school councils.

Earlier education initiatives tended to focus entirely on the provision of school inputs related to infrastructure; these inputs were seldom linked to increased enrollment and student performance. In particular, the Social Action Program (SAP) — comprising SAP-I and SAP-II started in 1993made large investments in school infrastructure over a period of almost 10 years, but there was hardly any evaluation of results. Considered mostly unsuccessful, the SAP suffered from a complex monitoring system and weak engagement of local leadership. Frequent political changes during that period created opportunities for corruption, and in general, donor dialogue and operations with the federal government took up most of the program's energy with less focus on the actual results (Khan, 1999). However, some lessons have been learned from the SAP in designing subsequent programs, mainly in devolving operations to local administrative units, avoiding corruption, paying attention to results, and setting up more efficient systems for planning and monitoring.

A more promising supply-side initiative was the contract teacher reform introduced in Punjab in 2002, in which all new teachers were hired on a contract renewable after five years based on their performance. There was evidence of learning gains from the use of contract teachers (Das \& Bau, 2011), but problems of policy design and implementation-such as frequent resignations by contract teachers and site-specific hiring-made it difficult to sustain the positive effects of the reform. Contract teachers generally had a lower status than tenured teachers despite their higher educational 
qualifications (Habib, 2010). Contract hiring was given up in 2011, mainly due to political pressure, and all teachers were regularized.

Since several developing countries have had a positive experience with contract teachers (Kingdon, Aslam, Rawal, \& Das, 2013), a more beneficial approach would have been to evaluate the policy and modify its design and implementation to correct for some of the problems encountered rather than abandoning it altogether. However, one positive outcome was that the practice of merit-based hiring (first introduced under the contract scheme) has been retained in hiring new teachers.

\subsubsection{Continuous Professional Development Program for Teachers and Teacher Bonus Scheme}

Teachers' role in improving learning in schools is addressed in this initiative. Until recently, teacher absenteeism was one of the major problems in effective education delivery. ${ }^{9}$ Better monitoring since the PESRP and Punjab schools roadmap has improved teacher attendance significantly, especially in urban schools. The Directorate for Staff Development introduced the Continuous Professional Development Program in 2004 in all 36 districts of Punjab as an in-service and professional development program for primary teachers.

This initiative follows a decentralized approach to teacher training with one district training support center for each district and district teacher educators covering 10-15 schools each. In this model of in-service teacher training, mentoring and support takes place in the school environment and in the context of the issues and problems of that particular school.

The abolition of training certification such as the Primary Teaching Certificate in Pakistan in 2002 has been an important step in removing ineffective training requirements, since the education literature indicates that teacher training in general does not raise student achievement (Darling-Hammond, 2013). The effectiveness of the innovative Continuous Professional Development Program and teacher bonus program will depend on how much more effort is invested in the classroom as a result of incentives in the scheme. There could be adverse effects if training requires teachers to spend less time on active teaching and if receiving bonuses encourages "teaching to the test." A significant

${ }^{9}$ Teacher absenteeism in Pakistan has been estimated to vary from 10 to 20 percent, with higher rates prevalent in rural areas (Chaudhury, Hammer, Kremer, Muralidharan, \& Rogers, 2006; Gazdar, 2000). 
finding of Andrabi, Das, and Khwaja (2010) is that teacher compensation is commensurate with teacher performance in private but not public schools, indicating better "pay-for-performance" incentive structures in private schools where it is possible to fire absent and nonperforming teachers irrespective of their qualifications, training, and seniority.

\subsubsection{Foundation-Assisted Schools}

As a public-private partnership initiative under the Punjab Education Foundation, "foundation-assisted schools" were designed to meet the increased demand for private schooling under the Education Voucher Scheme. These schools are monitored for quality assurance and public subsidies are continued on the basis of schools achieving a minimum pass rate after two test rounds. An impact evaluation of the initiative from 2008 to 2011 found that enrollment in foundation-assisted schools had increased by 40 percent and that student achievement had improved by the equivalent of one to two additional years of schooling. Substantial increases in learning were observed between the two test rounds due to the pressure of a highstakes test (Barrera-Osorio \& Raju, 2010).

\subsubsection{Report Cards and Student Learning Assessment}

The PEC has been undertaking student learning assessments for grades 5 and 8 since 2003, made mandatory from 2005 in all private and public schools. Punjab is the first province to launch a large-scale assessment program. In a study combining 2009 data on school characteristics with PEC scores, Andrabi et al. (2012) attempt to link student performance to school inputs. The authors find variations at the school level to be important in explaining differences in student achievement: "The gap between good and bad district is relatively smaller compared to the gap between good and bad schools within any given district." Factors associated with better student performance are lower student-teacher ratios, better-educated and more experienced teachers, and better school facilities such as blackboards. Moreover,

districts with higher enrollments do not necessarily have better child learning results.

The variation in quality across schools calls for greater focus on school-level factors that could help explain why some government and private schools are better than others and how the characteristics of these schools affect learning. 


\subsubsection{Medium of Instruction}

The results of the PEC exams show language achievement test scores to be particularly low. The lack of a clear language policy has probably had a detrimental effect on learning. The Punjab government announced a policy of English-medium instruction at the primary level in 2006 to address parental demand, gauged by the increased demand for private schools offering instruction in English. Government schools and teachers were not prepared for this drastic policy change: teachers' knowledge of English was limited and textbooks and curricula were not developed for teaching subjects in English. As a result of this policy, math and science teachers started asking to be switched to teaching Urdu because of their lack of English skills (Bari, 2013). More than 50 languages are spoken across Pakistan and a clearer language policy in schools is needed based on a consensus of views and local demand. ${ }^{10}$

Parents demand English-medium education mainly for its perceived usefulness in access to job opportunities and in reducing social inequality. At the same time, national and indigenous languages are considered an important part of belonging to a community and of a student's identity (Ahmed et al., 2013; Rahman, 2010). Rather than engaging in emotional debates, it is important to take practical steps to develop language training facilities and curricula that incorporate at least two languages (English, Urdu, and a local language) in school instruction to promote meaningful learning.

\subsubsection{Introduction of High-Stakes Testing}

To improve the quality of learning, significant weight is given to PEC test scores in ranking districts and approving subsidies for foundation-assisted schools. However, the disadvantages of high-stakes testing have been shown to encourage teaching a narrowly focused curriculum that emphasizes test preparation. School systems have also tended to prevent academically weaker students from sitting high-stakes tests (Figlio \& Getzler, 2006). Better evaluation of the PEC assessment system is required to ensure that testing is not geared to fulfilling mainly bureaucratic and political aims and that it is used to enhance students' subject knowledge and academic skills.

\footnotetext{
${ }^{10}$ The experience of other countries with multilingual backgrounds could be useful in developing a language policy for the medium of instruction. For instance, India follows a "three-language formula" (Annamalai, 2001) and in several developing countries where there is a demand for competence in English, schools have bilingual language policies (Garcia, 2008; Klaus, 2003).
} 
A monitoring study by the Society for Advancement in Higher Education (2011), conducted in 3,000 examination centers in 18 districts over a period of one year, reveals the weaknesses of the examination system: the lack of clear checking guidelines; too many exams held in one day; undue stress on teachers and students; and the absence of proper facilities at exam centers, such as furniture, bathrooms, and electricity. The current pass percentage of 33 percent is also considered too low as it reflects a poor standard of achievement. The study recommends that linking teacher accountability to students' test scores alone should be avoided, given some of the reliability and validity issues that hamper the assessment system. Problems with "teaching to the test" experienced in other countries that use high-stakes assessment systems imply that investing in foundation-assisted schools could be counterproductive if favorable learning results are achieved mainly on the basis of teaching a narrow curriculum.

\subsubsection{School Councils and Head Teacher Leadership}

Several studies emphasize the importance of supply-side schoolrelated factors in access and learning. As part of the devolution program and in an attempt to involve communities in school management and accountability, 56,000 school councils were formed in 2009. These councils receive annual grants to improve school infrastructure. Council members comprise the head teacher, parents, and local citizens who monitor the performance of teachers and school results; the head teacher is given a prominent role in this. Annual grants ranging from PRs 20,000 to PRs 50,000 are provided at various schooling levels to address the needs of particular schools. As a step toward greater focus on activities and structures within schools, strengthening school councils and conducting research on initiatives at the school level would help identify some of the characteristics that make schools better or worse.

\subsubsection{School Environment}

Parents' demand for schooling and students' motivation to learn and continue their education is influenced greatly by the quality of schools available. Much more attention needs to be focused on activities and structures within schools. An intervention under the Private-Public Partnership program addressed the problem of rote learning and low standards in schools by introducing a "child-friendly" class environment (Naseer, Patnam, \& Raza, 2010). Teacher and principal training was

offered twice a year, and technical assistance provided throughout the 
school year. Materials such as prisms and building blocks were also provided and activities such as book making and dramatic play introduced. Schools where the intervention was introduced were found to have higher learning scores than nonprogram schools.

\subsubsection{Curriculum Standards and Coverage}

A crucial supply-side constraint in providing better-quality education is an appropriate curriculum. An effort to raise standards by developing an improved school curriculum was undertaken in 2006 at a national level; since devolution, the provinces have implemented some changes from the new curriculum. However, problems associated with curricula, as identified in several research studies, have yet to be addressed. Studies on Africa and South Asia (including Pakistan) show that covering too much material too quickly can have an adverse effect on cumulative student learning. As a result, students do not master the basics despite several years of instruction (Pritchett \& Beatty, 2012). Not only is it therefore important to develop a high-standard curriculum, but it is also important to pace the instruction of class materials for children to be able to master basic concepts in elementary grades.

\section{Concluding Remarks}

Although Punjab has a more advanced education system than the other provinces, most of its people remain poorly educated despite numerous education policies and reforms. On average, about a quarter of school-age children are not enrolled, fewer girls than boys attend school, and learning outcomes are inadequate. Increased expenditures are required to meet the cost of an expanded and improved school system, but incurring more expense in itself is not likely to yield positive results in the absence of better governance and a clearer vision of the goals of education.

The process of devolving education to provincial and district governments via the $18^{\text {th }}$ Amendment to the Constitution provides an opportunity to shift governance and administrative structures in education closer to the communities that will benefit from them. Parents' demand for quality education is reflected in the rapid spread of private schooling throughout the country for families of all income levels. Devolution is expected to help articulate the purpose of education to more effectively match the supply of education with demand for the large numbers of children in need of schooling within the array of Pakistani ethnic and geographical contexts. 
Major investments in education are currently taking place under the PESRP and Punjab Schools Roadmap. The stated goals of access, quality, and retention can be assessed within a framework of household-, school-, and community-level factors that affect these goals. The education literature indicates that, on the demand side, poverty remains an overwhelming constraint to school attendance in Punjab. Schooling quality, school location, and teacher presence affect parents' decision to send their children to school. Important supply issues include appropriate and high-quality curricula, the presence and effectiveness of teachers, and efficient school management.

Past initiatives in education were driven by expenditure on school infrastructure with limited evaluation of results. Recent reform programs have incorporated lessons from past failures such as the SAP, and are aiming to build better monitoring and governance structures that include student assessments. On the other hand, a better evaluation of past policies is needed as they are implemented. Under the PESRP, the policy of contract hiring was shelved despite positive results in teacher attendance and student achievement. Rather than addressing the implementation problems and inherent contradictions in policy design that were causing teacher dissatisfaction, political pressure led to the policy being abandoned altogether and all contract teachers being regularized.

A number of education reform initiatives are currently in progress in Punjab. Some of these, such as the girls' secondary stipend program, have been partially successful in that enrollments and attendance levels have improved as a result. Learning levels, however, have remained the same. Extending merit-based voucher and CCT programs to girls may help address the problem of lower female participation and improve learning.

To address the issue of low learning standards, an innovative inservice teacher professional development program has been introduced, and testing takes place regularly in grades 5 and 8 to monitor students' progress. Student and teacher attendance as well as test scores have improved since 2011, mainly due to better supervision and monitoring.

However, these assessments involve high-stakes tests that link student and teacher performance to rewards and punishments for teachers and schools. This creates incentives for teaching a narrowly focused curriculum aimed at "teaching to the test" and for gaming the system by excluding poorly performing students. Math and language skills remain low, as gauged by independent evaluations such as ASER (2013) and the official Punjab Education Department statistics. 
Research studies on Punjab's educational system and evaluations of similar reform initiatives in other countries point to a number of factors that need to be addressed to remedy poor learning levels. These factors could be incorporated in the several innovative approaches currently in place under the PESRP and Punjab Schools Roadmap such as lesson plans, publicprivate partnerships, teacher in-service mentoring, and school councils.

1. Existing lesson plans in earlier grades should be modified to ensure that students master basic concepts and build a solid educational foundation. This will require considerable effort by teachers and school administrators as well as parents, to ensure teacher presence in the classroom, teacher competence in subject knowledge, and the ability to create a comfortable and inclusive learning environment for students.

2. Classes usually have a student mix of different ages and competency levels. Remedial programs may be required to ensure that the majority of students are receptive to teaching at grade-appropriate standards.

3. Exam results show low proficiency in students' language competence. Further policy debate and research is required to develop a multilingual policy incorporating English, Urdu, as well as local languages. This would fulfill multiple aims of education by increasing employment opportunities while remaining integrated with national and local identity and culture.

4. Less emphasis on high-stakes assessments will take pressure off district administrators and teachers to achieve results quickly under threat of dismissal, transfer, or lack of financial rewards. Testing should be geared to raising actual learning levels.

Few rigorous evaluations of educational initiatives have been conducted for programs implemented in Punjab and in Pakistan. For greater accuracy in assessing program results, baseline data needs to be collected on variables of interest and other factors that might influence outcomes; the counterfactual also needs to be built for meaningful comparison of results. Revisions in implementation and policy design can be based on these evaluations.

Educational investments show results over time. Education budgets usually suffer cutbacks along with other public sector development programs during periods of economic downturn. To prevent the early dissipation of educational benefits, investments in education have to follow overall school, district, provincial, and national goals and continue over a period of time despite political and economic setbacks. 


\section{References}

Ahmed, H., Amjad, S., Habib, M., \& Shah, S. A. (2013). Determinants of school choice: Evidence from rural Punjab, Pakistan (Working Paper No. 01-13). Lahore, Pakistan: Centre for Research in Economics and Business.

Alderman, H., Orazem, P. F., \& Paterno, E. M. (2001). School quality, school cost, and the public/private school choices of low-income households in Pakistan. Journal of Human Resources, 36(2), 304-326.

Andrabi, T., Das, J., \& Khwaja, A. I. (2010). Education policy in Pakistan: A framework for reform: A policy brief. London, UK: International Growth Centre.

Andrabi, T., Das, J., Khwaja, A. I., Vishwanath, T., \& Zajonc, T. (2007). Learning and educational achievements in Punjab schools (LEAPS): Insights to inform the education policy debate. Washington, DC: World Bank.

Andrabi, T., Khan, S., Khan, Y., \& Naseer, M. F. (2012). Learning in public schools (Working Paper No. 12/0390). London, UK: International Growth Centre.

Annamalai, E. (2001). Managing multilingualism in India: Political and linguistic manifestations. New Delhi, India: SAGE.

Annual Status of Education Report. (2012). Annual status of education report: ASER-Pakistan 2011. Lahore, Pakistan: Author.

Annual Status of Education Report. (2013). Annual status of education report: ASER-Pakistan 2012. Lahore, Pakistan: Author.

Asadullah, M. N. (2009). Returns to private and public education in Bangladesh and Pakistan: A comparative analysis. Journal of Asian Economics, 20(1), 77-86.

Aslam, M. (2009). Education gender gaps in Pakistan: Is the labor market to blame? Economic Development and Cultural Change, 57(4), 747-784.

Barber, M. (2013). The good news from Pakistan: How a revolutionary new approach to education reform in Punjab shows the way forward for Pakistan and development aid everywhere. London, UK: Reform Research Trust. 
Bari, F. (2013, June 21). In which medium? Dawn.

Barrera-Osorio, F., \& Filmer, D. (2012). Incentivizing schooling for learning: Evidence on the impact of alternative targeting approaches. Unpublished manuscript. Retrieved from http://www.bu.edu/econ/files/2010/ 08/Incentivizing_schooling_cambodia_V5.pdf

Barrera-Osorio, F., \& Raju, D. (2010). Short-run learning dynamics under a test-based accountability system: Evidence from Pakistan (Policy Research Working Paper No. 5465). Washington, DC: World Bank.

Bengali, K. (1999). History of education policymaking and planning in Pakistan (Working Paper No. 40). Islamabad, Pakistan: Sustainable Development Policy Institute.

Chaudhury, N., Hammer, J., Kremer, M., Muralidharan, K., \& Rogers, F. H. (2006). Missing in action: Teacher and health worker absence in developing countries. Journal of Economic Perspectives, 20(1), 91-116.

Chaudhury, N., \& Parajuli, D. (2010). Conditional cash transfers and female schooling: The impact of the female school stipend program on public school enrolments in Punjab, Pakistan. Applied Economics, 42(28), 3565-3583.

Cummings, W. K. (2003). The institutions of education: A comparative study of educational development in the six core nations (Oxford Studies in Comparative Education). Oxford, UK: Symposium Books.

Darling-Hammond, L. (2013, June 18). National Council on Teacher Quality report is deeply flawed. EdSource. Retrieved from http://www.edsource.org/today/2013/national-council-onteacher-quality-report-is-deeply-flawed/33770

Das, J., \& Bau, N. (2011, November). Buy more, pay less: Measuring the performance of Pakistani contract teachers. Paper presented at NEUDC Conference, Yale University, New Haven, CT. Retrieved from $<$ http://www.econ.yale.edu/conference/neudc11/papers/paper_ 116.pdf $>$.

Das, J., Pandey, P., \& Zajonc, T. (2006). Learning levels and gaps in Pakistan (Policy Research Working Paper No. 4067). Washington, DC: World Bank. 
Dreze, J., \& Sen, A. (2013). An uncertain glory: India and its contradictions. Princeton, NJ: Allen Lane and Princeton University Press.

Figlio, D. N., \& Getzler, L. S. (2006). Accountability, ability and disability: Gaming the system? Advances in Applied Microeconomics, 14, 35-49.

Filmer, D., \& Schady, N. (2011). Does more cash in conditional cash transfer programs always lead to larger impacts on school attendance? Journal of Development Economics, 96(1), 150-157.

Garcia, O. (2008). Bilingual education in the 21st century: A global perspective. Malden, MA: Wiley-Blackwell.

Gazdar, H. (2000). State, community, and universal education: A political economy of public schooling in rural Pakistan (Mimeo). London, UK: London School of Economics and Political Science, Asia Research Centre.

Glewwe, P. W., Hanushek, E. A., Humpage, S. D., \& Ravina, R. (2011). School resources and educational outcomes in developing countries: A review of the literature from 1990 to 2010 (Working Paper No. 17554). Cambridge, MA: National Bureau of Economic Research.

Glewwe, P., \& Kremer, M. (2006). Schools, teachers, and education outcomes in developing countries. In E. Hanushek \& F. Welch (Eds.), Handbook of the economics of education (vol. 2). Amsterdam: Elsevier.

Habib, M. (2010). The impact of 2002 national teacher contract policy reform on teacher absenteeism in Lahore, Pakistan. Unpublished doctoral dissertation, George Washington University, Washington, DC.

Khan, S. R. (1999). An overview of basic education under the Social Action Program in Pakistan (Research Report No. 22). Islamabad, Pakistan: Social Development Policy Institute.

Kingdon, G., Aslam, M., Rawal, S., \& Das, S. (2013). Are contract teachers and para-teachers a cost-effective intervention to address teacher shortage and improve learning outcomes? London, UK: University of London, Institute of Education. 
Klaus, D. (2003). The use of indigenous languages in early basic education in Papua New Guinea: A model for elsewhere? Language and Education, 17(2), 105-111.

Lloyd, C., Mete, C., \& Grant, M. (2007). Rural girls in Pakistan: Constraints of policy and culture. In M. Lewis \& M. Lockheed (Eds.), Exclusion, gender and education: Case studies from the developing world. Washington, DC: Center for Global Development.

Lynd, D. (2007). The education system in Pakistan: Assessment of the National Education Census. Islamabad, Pakistan: United Nations Educational, Scientific, and Cultural Organization.

Nabi, I. (2013, March). Two social protection programs in Pakistan. Paper presented at the Ninth Annual Conference of the Lahore School of Economics, Lahore, Pakistan.

Naseer, M. F., Patnam, M., \& Raza, R. (2010). Transforming public schools: Impact of the CRI program on child learning in Pakistan. Economics of Education Review, 29, 669-683.

Orazem, P. F., \& King, E. M. (2007). Schooling in developing countries: The roles of supply, demand and government policy. In T. P. Schultz \& J. A. Strauss (Eds.), Handbook of development economics (vol. 4, pp. 3475-3559). Amsterdam: Elsevier.

Pakistan Bureau of Statistics. (2001). Census of private educational institutions in Pakistan 1999-2000. Islamabad, Pakistan: Author.

Pakistan Bureau of Statistics. (2010). Pakistan social and living standards measurement survey 2008-09. Islamabad, Pakistan: Author.

Pakistan Bureau of Statistics. (2011). Pakistan social and living standards measurement survey 2010-11. Islamabad, Pakistan: Author.

Pakistan, Finance Division. (2011). Pakistan economic survey 2010-11 (chap. 12). Islamabad, Pakistan: Author. Retrieved from http:/ / www.finance.gov.pk/survey/ chapter_12/highlights.pdf

Pakistan, Ministry of Education and Training. (2013). Country report Pakistan 2013-15: Accelerating Millennium Development Goals. Islamabad, Pakistan: Author. 
Pritchett, L. (2001). Where has all the education gone? World Bank Economic Review, 15(3), 367-391.

Pritchett, L., \& Beatty, A. (2012). The negative consequences of overambitious curricula in developing countries (Working Paper No. 293). Washington, DC: Center for Global Development.

Punjab, School Education Department. (2011a). Punjab education assessment system (PEAS): District-wide large-scale assessment [DWLSA] report 2011. Lahore, Pakistan: Author.

Punjab, School Education Department. (2011b). School Education Department [Webpage]. Retrieved from http:/ / schoolportal.punjab.gov.pk/schoolcensusNew.htm

Rahman, T. (2010). Denizens of alien worlds: A study of education, inequality and polarization in Pakistan. Karachi, Pakistan: Oxford University Press.

Society for Advancement in Higher Education. (2011). Improving education through large-scale testing? A study on primary and elementary level exams in Punjab. Lahore, Pakistan: Author.

World Bank. (2012). World development indicators 2012. Washington, DC: Author. 